\title{
Article \\ Genome-Wide Identification and Characterization of Calcium-Dependent Protein Kinase (CDPK) and CDPK-Related Kinase (CRK) Gene Families in Medicago truncatula
}

\author{
Pengcheng Zhao, Yajie Liu, Weiyi Kong, Jiayi Ji, Tianyu Cai and Zhenfei Guo *(i) \\ College of Grassland Science, Nanjing Agricultural University, Nanjing 210095, China; \\ 2016220006@njau.edu.cn (P.Z.); 2018120001@njau.edu.cn (Y.L.); T2017076@njau.edu.cn (W.K.); \\ 15517125@njau.edu.cn (J.J.); 15517132@njau.edu.cn (T.C.) \\ * Correspondence: zfguo@njau.edu.cn; Tel.: +86-02-58-439-6101
}

Citation: Zhao, P.; Liu, Y.; Kong, W.; Ji, J.; Cai, T.; Guo, Z. Genome-Wide Identification and Characterization of Calcium-Dependent Protein Kinase (CDPK) and CDPK-Related Kinase (CRK) Gene Families in Medicago truncatula. Int. J. Mol. Sci. 2021, 22, 1044. https://doi.org/10.3390/ ijms22031044

Received: 9 November 2020

Accepted: 14 January 2021

Published: 21 January 2021

Publisher's Note: MDPI stays neutral with regard to jurisdictional claims in published maps and institutional affiliations.

Copyright: () 2021 by the authors. Licensee MDPI, Basel, Switzerland. This article is an open access article distributed under the terms and conditions of the Creative Commons Attribution (CC BY) license (https:// creativecommons.org/licenses/by/ $4.0 /)$.

\begin{abstract}
Calcium-dependent protein kinase (CDPK or CPK) and CDPK-related kinase (CRK) play an important role in plant growth, development, and adaptation to environmental stresses. However, their gene families had been yet inadequately investigated in Medicago truncatula. In this study, six MtCRK genes were computationally identified, they were classified into five groups with $M t C D P K s$ based on phylogenetic relationships. Six pairs of segmental duplications were observed in $M t C D P K$ and MtCRK genes and the Ka/Ks ratio, an indicator of selection pressure, was below 0.310 , indicating that these gene pairs underwent strong purifying selection. Cis-acting elements of morphogenesis, multiple hormone responses, and abiotic stresses were predicted in the promoter region. The spatial expression of $M t C D P K s$ and $M t C R K s$ displays diversity. The expression of $M t C D P K s$ and MtCRKs could be regulated by various stresses. MtCDPK4, 14, 16, 22, and MtCRK6 harbor both $\mathrm{N}$-myristoylation site and palmitoylation site and were anchored on plasma membrane, while MtCDPK7, 9, and 15 contain no or only one $\mathrm{N}$-acylation site and were distributed in cytosol and nucleus, suggesting that the N-terminal acylation sites play a key role in subcellular localization of MtCDPKs and MtCRKs. In summary, comprehensive characterization of MtCDPKs and MtCRKs provide a subset of candidate genes for further functional analysis and genetic improvement against drought, cold, salt and biotic stress.
\end{abstract}

Keywords: genome-wide analysis; Medicago truncatula; CDPK; CRK; cis-acting elements; expression pattern; subcellular localization

\section{Introduction}

Calcium is a ubiquitous second messenger in plant cells involving in growth, development, and responses to environmental stresses [1]. The external signals lead to a transient increased free $\mathrm{Ca}^{2+}$ concentration in the cytosol. $\mathrm{Ca}^{2+}$ is bound with calcium binding proteins $(\mathrm{CBP})$, or $\mathrm{Ca}^{2+}$ sensors, which decode the signals and lead to cellular alterations in biochemical and physiological processes [2-4]. There are five types of $\mathrm{Ca}^{2+}$ sensors in plants, including calmodulin (CaM), calmodulin-like protein (CML), calcineurin B-like protein (CBL), calcium/calmodulin-dependent protein kinase (CCaMK) [5], and calcium-dependent protein kinase (CDPK) [6]. Compared to CaM, CML, and CBL, CDPKs directly transduce $\mathrm{Ca}^{2+}$ signal into phosphorylation cascades, which makes CDPKs have a dual function: $\mathrm{Ca}^{2+}$ sensors and responders [7].

CDPKs exist in higher plants, green algae, oomycetes, and protists, but absent in animals and fungi [8], while CRKs are only observed in plants [9]. CDPK harbors four domains: an N-terminal variable domain, a protein kinase domain, an autoinhibitory junction region, and a calmodulin-like domain (CaM-LD) which commonly containing four EF-hands [10]. CRK has a similar protein structure to CDPK with a degenerative CaM-LD, which causes the inability to bind $\mathrm{Ca}^{2+}[7]$. There is generally an $\mathrm{N}$-myristoylation site and 
a palmitoylation site in the $\mathrm{N}$-terminal variable domain. $\mathrm{N}$-myristoylation is irreversible and provides a loose membrane association, while palmitoylation is reversible and confers stable membrane anchoring [11]. The membrane binding ability of CDPKs is decreased when the palmitoylation or myristoylation site is mutated [12].

CDPKs and CRKs participate in regulation of multiple physiological processes. They are involved in pollen tube elongation [13], seedling and leaf development [14], shoot and root hairs development [15,16], root growth and gravitropism [17,18], flowering [19], seed development [20], and senescence-related cell death [21]. CDPKs and CRKs are involved in the responses to abiotic stresses. For example, CDPKs are involved in drought or salt stress adaptation through inducing $\mathrm{ABF}-$ mediated $\mathrm{ABA}$-responsive gene expression and regulating ABA-induced anion channel (SLAC1, SLAH3) to modulate stomatal closure in Arabidopsis [22,23]. CDPKs activate the enzymatic reactive oxygen species (ROS) scavenging pathways to regulate drought and salt adaptation. Catalase CAT3 is phosphorylated by AtCPK8 for activating its activity in Arabidopsis [24], while ascorbate peroxidase OsAPX2/OsAPX8 and NADPH oxidase OsrbohI expression is regulated by OsCPK12 in rice [25]. Moreover, vacuolar $\mathrm{K}^{+}$channel TPK1 is phosphorylated by AtCPK3 to regulate the cytosolic $\mathrm{K}^{+} / \mathrm{Na}^{+}$balance in responses to salt stress [26]. OsCPK17 participates in cold stress response through interacting with aquaporin OsPIP2;1/OsPIP2;6 and sucrosephosphate synthase OsSPS4 [27]. GmCDPKSK5 in response to high temperature and humidity stress during soybean seed development through targeting translationally controlled tumor protein GmTCTP [28]. AtCRK1 is involved in maintaining cellular redox homeostasis and osmotic balance under continuous illumination and salt stress, respectively [18,29]. AtCRK1 is a positive regulator of thermotolerance by phosphorylation of AtHSFA1a to increase heat-shock transcription factor (HSF) DNA binding to the heat-shock element (HSE) [30]. CDPKs and CRKs have been reported in responses to biotic stresses. AtCPK1 affects the accumulation of salicylic acid (SA) and further induces expression of SA-regulated defense genes against fungus and bacterial pathogens [31]. AtCPK5, AtCPK6, and AtCPK11 affect Botrytis cinereal infection via inducing ethylene production through modulating the transcriptional level of ethylene biosynthesis enzyme ACC synthase ACS2 and ACS6 [32]. AtCPK5 phosphorylates NADPH oxidase homolog D (RBOHD) and leads to the production of extracellular $\mathrm{H}_{2} \mathrm{O}_{2}$, which is crucial for accelerating rapid signal propagation to defense response activation [33]. SICRK6 is a positive regulator of Pst DC3000 and Sclerotinia sclerotiorum resistance in tomato [34]. MtCDPK8, 16, and 19 were reported to regulate root nodule development via symbiotic interaction in M. truncatula [35-37]. CDPK and CRK families have been demonstrated as key regulators in various signaling pathways in many plant species [38,39]. However, comprehensive bioinformatics analysis in M. truncatula, a legume model plant, had been yet inadequately investigated. Although $25 \mathrm{MtCDPK}$ genes were identified and characterized [40], they were not named using a standard procedure and were not characterized for gene duplication, cis-acting elements, and subcellular localization. In addition, MtCRK genes have not been investigated.

The objectives of this study were to investigate the gene structure, conserved motifs, phylogenetic relationship, chromosome distribution, gene duplication, and cis-acting regulatory elements of $M t C D P K$ and $M t C R K$ gene families in M. truncatula and to analyze their spatial expression profiles and response to abiotic and biotic stresses. In addition, the subcellular localization of selected MtCDPKs and MtCRKs were analyzed to explore the role of N-terminal acylation in protein localization.

\section{Results}

\subsection{Identification of $M t C R K$ Genes}

A genome-wide analysis of $M t C R K$ gene families was performed based on M. truncatula genome sequences using HMMER3.0, SMART, and CDD software. A total of six MtCRKs were perceived from $M$. truncatula genome. They and previously identified MtCDPKs were denominated as MtCDPK1 to MtCDPK24 and MtCRK1 to MtCRK6, respectively, depending 
on their chromosomal positions (Table 1). Except for the CaM-like domain consisting of zero to three EF-hands, MtCRKs share the similar domain with MtCDPKs (Table 1).

Table 1. Characteristics of CDPK and CRK genes in Medicago truncatula.

\begin{tabular}{|c|c|c|c|c|c|c|c|c|}
\hline Gene Name & Gene ID & Chromosome Location & $\begin{array}{l}\text { No. } \\
\text { of aa }\end{array}$ & $\begin{array}{c}\text { MW } \\
(\mathbf{k D a})\end{array}$ & pI & GRAVY & $\begin{array}{l}\text { No. of EF } \\
\text { Hands }\end{array}$ & $\begin{array}{l}\text { N-Acylation Prediction } \\
\text { (No.) }\end{array}$ \\
\hline$M t C D P K 1$ & Medtr0028s0170.1 & scaffold0028:72630..76559 & 534 & 59.85 & 5.65 & -0.542 & 4 & N-Myr (1)-Palm (2) \\
\hline$M t C D P K 2$ & Medtr1g026190.1 & chr1:8404402..8408507 & 533 & 60.47 & 6.21 & -0.591 & 4 & N-Myr (1)-Palm (1) \\
\hline$M t C D P K 3$ & Medtr1g041150.1 & chr1:18398807..18403890 & 581 & 65.08 & 5.37 & -0.376 & 4 & N-Myr (1)-Palm (1) \\
\hline$M t C D P K 4$ & Medtr1g052530.1 & chr1:21386135..21390691 & 528 & 60.13 & 6.16 & -0.501 & 4 & N-Myr (1)-Palm (2) \\
\hline$M t C D P K 5$ & Medtr1g054865.1 & chr1:24041840..24046332 & 607 & 66.45 & 5.51 & -0.334 & 4 & N-Myr (1)-Palm (1) \\
\hline$M t C D P K 6$ & Medtr1g055255.1 & chr1:24417898..24422244 & 589 & 66.07 & 6.52 & -0.478 & 4 & N-Myr (2)-Palm (1) \\
\hline$M t C D P K 7$ & Medtr1g096490.1 & chr1:43462266..43465665 & 499 & 56.18 & 5.21 & -0.380 & 4 & N-Palm (1) \\
\hline$M t C D P K 8$ & Medtr3g051770.1 & chr3:20500557..20506458 & 538 & 60.60 & 5.77 & -0.460 & 4 & N-Myr (1)-Palm (1) \\
\hline$M t C D P K 9$ & Medtr3g098070.1 & chr3:44756354..44761409 & 495 & 55.92 & 5.17 & -0.342 & 4 & $-(0)$ \\
\hline$M t C D P K 10$ & Medtr3g098090.1 & chr3:44766535..44770211 & 498 & 56.37 & 5.36 & -0.395 & 4 & $-(0)$ \\
\hline MtCDPK11 & Medtr4g066660.1 & chr4:25214155..25217596 & 545 & 62.02 & 6.06 & -0.549 & 4 & N-Myr (1)-Palm (1) \\
\hline MtCDPK12 & Medtr4g107490.1 & chr4:44509014..44514153 & 555 & 63.02 & 6.37 & -0.470 & 4 & N-Myr (1)-Palm (2) \\
\hline MtCDPK13 & Medtr4g132040.1 & chr4:55151186..55153959 & 543 & 60.88 & 5.83 & -0.415 & 4 & N-Myr (1)-Palm (1) \\
\hline MtCDPK14 & Medtr4g132070.1 & chr4:55167475..55172407 & 539 & 60.56 & 6.16 & -0.463 & 4 & N-Myr (1)-Palm (1) \\
\hline MtCDPK15 & Medtr5g009830.1 & chr5:2478209..2483414 & 517 & 58.73 & 6.44 & -0.534 & 4 & $N-\operatorname{Myr}(1)$ \\
\hline$M t C D P K 16$ & Medtr5g022030.1 & chr5:8628890..8634949 & 560 & 63.50 & 9.10 & -0.615 & 4 & N-Myr (1)-Palm (1) \\
\hline MtCDPK17 & Medtr5g089320.1 & chr5:38807982..38811203 & 523 & 58.50 & 5.43 & -0.535 & 4 & N-Myr (1)-Palm (2) \\
\hline MtCDPK18 & Medtr5g092810.1 & chr5:40530948..40535829 & 540 & 61.32 & 7.67 & -0.615 & 4 & N-Myr (2)-Palm (1) \\
\hline MtCDPK19 & Medtr5g099240.1 & chr5:43501966..43509933 & 559 & 62.93 & 5.68 & -0.443 & 4 & N-Myr (1)-Palm (1) \\
\hline$M t C D P K 20$ & Medtr7g068710.1 & chr7:25219104..25225477 & 530 & 59.97 & 6.03 & -0.457 & 4 & N-Myr (1)-Palm (2) \\
\hline$M t C D P K 21$ & Medtr7g091890.1 & chr7:36380965..36385094 & 533 & 60.59 & 6.16 & -0.554 & 4 & N-Myr (1)-Palm (2) \\
\hline MtCDPK22 & Medtr7g106710.1 & chr7:43452426..43456560 & 602 & 68.15 & 5.34 & -0.451 & 4 & N-Myr (1)-Palm (1) \\
\hline$M t C D P K 23$ & Medtr8g095440.1 & chr8:39939663..39944572 & 503 & 56.82 & 5.20 & -0.344 & 4 & $-(0)$ \\
\hline$M t C D P K 24$ & Medtr8g099095.1 & chr8:41618323..41623707 & 516 & 58.06 & 5.93 & -0.410 & 4 & N-Myr (1)-Palm (1) \\
\hline$M t C R K 1$ & Medtr3g092230.1 & chr3:42122948..42129657 & 588 & 65.61 & 8.74 & -0.318 & 0 & N-Myr (1)-Palm (2) \\
\hline$M t C R K 2$ & Medtr4g086660.1 & chr4:33966651..33972436 & 592 & 66.57 & 9.07 & -0.398 & 0 & N-Myr (2)-Palm (1) \\
\hline$M t C R K 3$ & Medtr5g017830.1 & chr5:6589564..6594550 & 587 & 65.86 & 8.49 & -0.309 & 2 & N-Myr (1)-Palm (1) \\
\hline$M t C R K 4$ & Medtr7g089480.1 & chr7:35036401..35042624 & 595 & 66.80 & 8.84 & -0.305 & 0 & N-Myr (1)-Palm (1) \\
\hline$M t C R K 5$ & Medtr7g118020.1 & chr7:48973096..48979529 & 596 & 66.62 & 8.92 & -0.415 & 3 & N-Myr (1)-Palm (1) \\
\hline$M t C R K 6$ & Medtr8g079790.1 & chr8:34200112..34204254 & 581 & 65.15 & 9.00 & -0.309 & 1 & N-Myr (1)-Palm (1) \\
\hline
\end{tabular}

The gene length of MtCRKs varies from $4143 \mathrm{bp}$ (MtCRK6) to $6710 \mathrm{bp}$ (MtCRK1), encoding protein length varies from 581 (MtCRK6) to 596 (MtCRK5) amino acids (aa). The molecular weight (MW) varies from 65.15 (MtCRK6) to $66.80 \mathrm{kDa}$ (MtCRK4), while the isoelectric point (pI) varies from 8.49 (MtCRK3) to 9.07 (MtCRK2), indicating that MtCRKs are alkaline. The grand average of hydropathy (GRAVY) ranges from -0.415 (MtCRK5) to -0.305 (MtCRK4), indicating that MtCRKs are hydrophilic. All MtCRKs contain both predicted N-terminal myristoylation and palmitoylation sites. In addition, most MtCDPKs harbor these predicted sites, while MtCDPK7 contains only a predicted palmitoylation site and MtCDPK15 contains a predicted myristoylation site. MtCDPK9, 10 and 23 were predicted to have neither myristoylation nor palmitoylation site (Table 1).

\subsection{Phylogenetic and Chromosomal Distribution of MtCDPKs and MtCRKs}

A neighbor-joining (NJ) phylogenic tree was constructed using CDPK and CRK sequences from M. truncatula, Arabidopsis, and rice. The sequences of CDPK and CRK were listed in Table S1. All proteins were clustered into five groups, including four groups of CDPK (CDPK I to CDPK IV) and one group of CRK (Figure 1).

The chromosomal location of MtCDPKs and MtCRKs was analyzed using TBtools software and gene annotation information. The results showed that MtCDPKs and MtCRKs are distributed on six chromosomes (Figure 2). Furthermore, the collinear correlation was calculated between $M$. truncatula and A. thaliana species to investigate the evolutionary history of CDPKs and CRKs. A total of 29 collinear gene pairs were found between $M$. truncatula and $A$. thaliana (Figure 2 and Table S2), indicating that these genes might have existed before the divergence between $M$. truncatula and $A$. thaliana. In addition, six gene pairs (MtCDPK6/22, MtCDPK8/18, MtCDPK9/23, MtCDPK15/24, MtCRK2/3, and 
MtCRK3/6) were found to be paralogous, indicating that they belonged to segmental duplications (Table 2). The selection pressure of the gene pairs was analyzed by computing the number of nonsynonymous substitutions per nonsynonymous site $(K a)$ and the number of synonymous substitutions per synonymous site (Ks) substitution rates (Table 2$)$. The $\mathrm{Ka} / \mathrm{Ks}$ value, an indicator for the selection history of these paralogous gene pairs, was below 0.310 (Table 2), indicating that these gene pairs underwent strong purifying selection in the evolutionary process, and led to the function of these gene pairs to be relatively conserved.

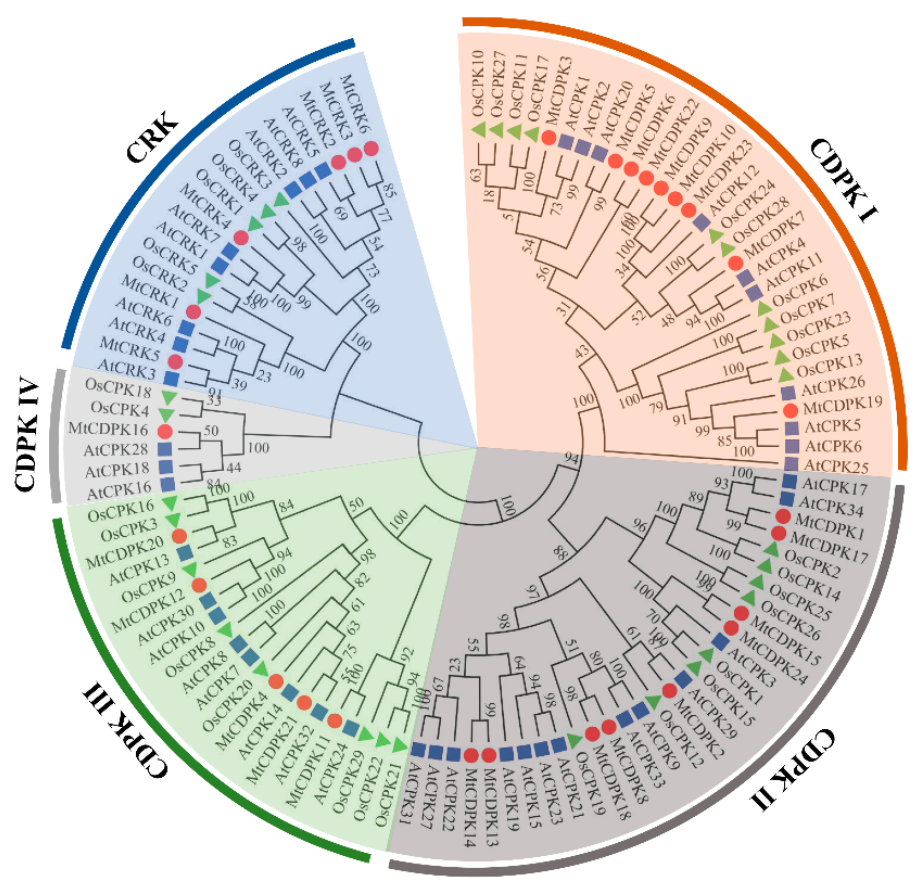

Figure 1. Phylogenetic relationships of CDPK and CRK proteins in M. truncatula (red circle), A. thaliana (blue square), and O. sativa (green triangle). The tree was constructed using MEGA7.0 software by the Neighbor-Joining method. The numbers next to the branch showed the 1000 bootstrap replicates expressed in percentage. The phylogenetic groups of MtCDPKs and MtCRKs were marked by different colors and legends.

Table 2. Duplications of the CDPK and CRK genes in Medicago truncatula.

\begin{tabular}{ccccccc}
\hline Gene 1 & Gene 2 & Ka & Ks & $\boldsymbol{K a} / \boldsymbol{K s}$ & Purifying Selection & Duplicate Type \\
\hline$M t C D P K 6$ & $M t C D P K 22$ & 0.243 & 0.791 & 0.307 & Yes & Segmental \\
$M t C D P K 8$ & $M t C D P K 18$ & 0.112 & 0.659 & 0.171 & Yes & Segmental \\
$M t C D P K 9$ & $M t C D P K 23$ & 0.100 & 0.720 & 0.139 & Yes & Segmental \\
$M t C D P K 15$ & $M t C D P K 24$ & 0.098 & 0.768 & 0.128 & Yes & Segmental \\
$M t C R K 2$ & $M t C R K 3$ & 0.168 & 1.936 & 0.087 & Yes & Segmental \\
$M t C R K 3$ & $M t C R K 6$ & 0.136 & 0.708 & 0.192 & Yes & Segmental \\
\hline
\end{tabular}




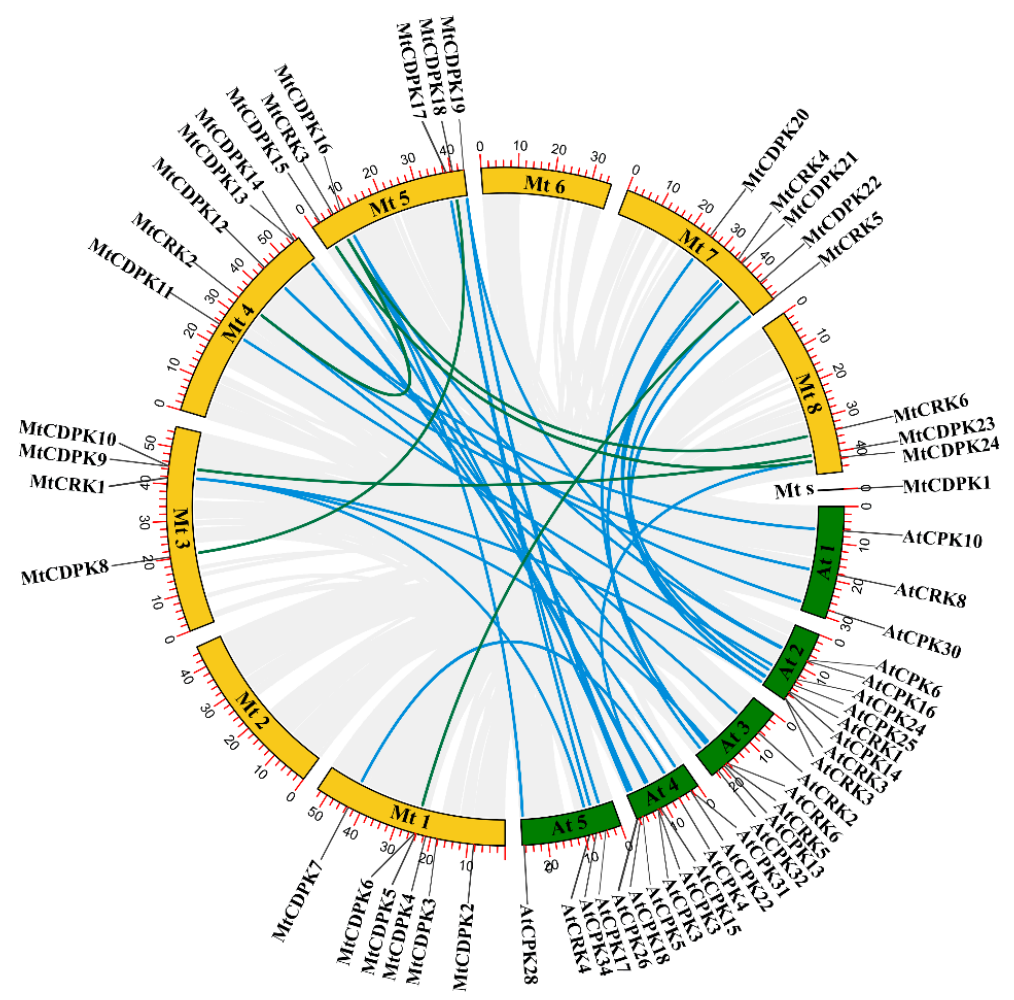

Figure 2. The collinear correlation of MtCDPKs and MtCRKs was displayed between M. truncatula and Arabidopsis genomes. The M. truncatula and Arabidopsis chromosomes were represented by yellow and green boxes, respectively. Collinear relationship of CDPKs and CRKs between M. truncatula and Arabidopsis indicated with blue lines, and within the M. truncatula genome indicated with green lines. s: M. truncatula scaffold0028.

\subsection{Analysis of Gene Structure and Conserved Motifs of MtCDPKs and MtCRKs}

The phylogenetic tree of MtCDPKs and MtCRKs was constructed (Figure 3A), which was consistent with that in Figure 1. Gene structure was analyzed based on the sequence in untranslated region (UTR), exon, and intron using TBTools. All genes have a long initial exon, followed by multiple short exons varying from seven to twelve in numbers, MtCRKs harbor more exons than MtCDPKs except for MtCDPK16 (Figure 3B). Interestingly, the exon-intron structure within the same group exhibits high similarity. For instance, all the genes in group CRK contain the identical number of exons and the same type of intron phase. MtCRKs had a similar intron-exon pattern with the members in CDPK IV group (Figure 3B).

The conserved motifs of MtCDPKs and MtCRKs were analyzed using the MEME program. Twenty conserved motifs varying from 8 to 50 aa. in lengths were observed. Only motif 16 was observed to be in the variable $\mathrm{N}$-terminal domain, while the myristoylation and palmitoylation sites were observed in the motif 16 in all MtCDPKs and MtCRKs except for MtCDPK15. The kinase domain showed conserved, and many motifs upstream the motif 5 were observed in the kinase domain. An auto-inhibitory junction region was existed in the motif 5, and the EF-hands were observed in the motif 5, 6, 8, 9, and 13 . The same conserved motifs were possessed by the members within the same group. The group-specific motifs were mainly observed at the $\mathrm{N}$-terminal and C-terminal of proteins. For example, motifs 13,15,17, 18, and 20 were present specifically in the members of CRK group except for MtCDPK16, while the motif 19 was in the members of CDPK III group. The above motifs were also present in the same group of CRK or CDPK in Arabidopsis and rice (Figure 3C and Figure S1, and Table S3). 
A

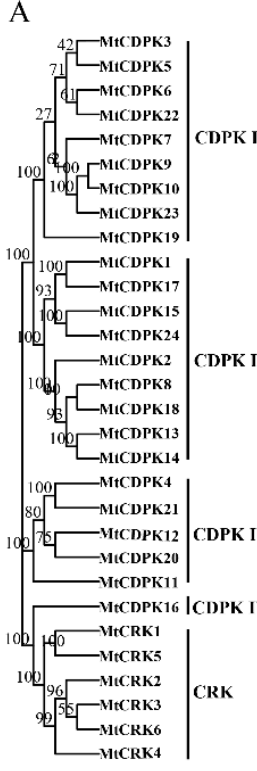

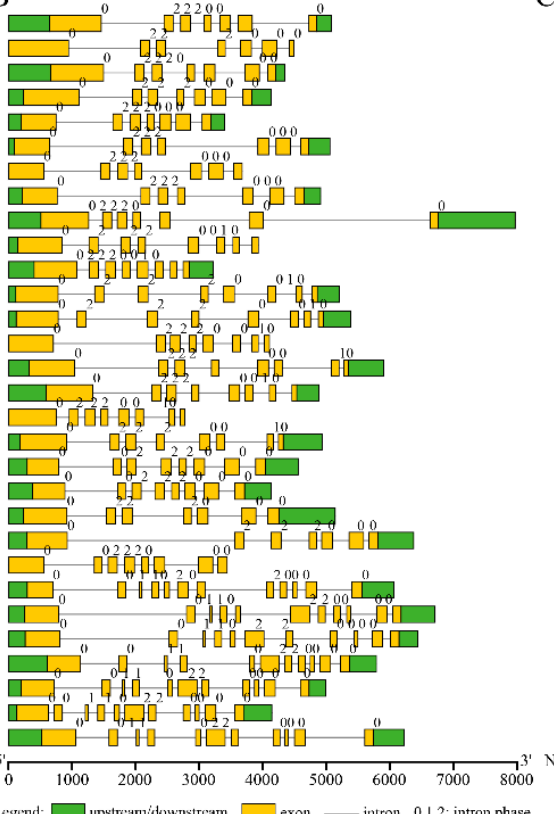

C

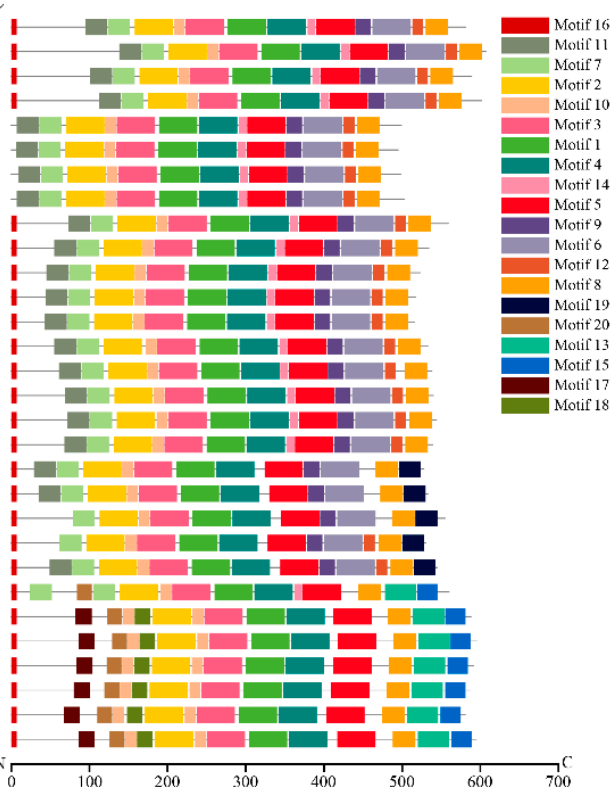

Figure 3. Phylogenetic relationship, gene structure, and conserved motifs of CDPKs and CRKs in M. truncatula. (A) The phylogenetic tree of MtCDPK and MtCRK proteins was constructed using MEGA7.0 software by the Neighbor-Joining method (1000 bootstrap replicates). (B) The gene structure of MtCDPK and MtCRK genes. The green boxes, yellow boxes, and black lines represent UTR, exon, and introns, respectively. Intron phases 0,1 , and 2 were labeled at the beginning of each intron. (C) The conserved motifs of MtCDPK and MtCRK proteins were identified using MEME. The motifs were indicated by different colored boxes and their numbers were listed on the right.

\subsection{Cis-Acting Elements in the Promoter Region of MtCDPKs and MtCRKs}

To gain insight into the potential function and regulatory mechanisms of the genes during plant development and responses to various stresses, the recognized putative cis-acting regulatory elements were analyzed from $2.0 \mathrm{~kb}$ DNA sequence in the promoter region of $M t C D P K$ and $M t C R K$ genes using the PlantCARE database. Various types of cis-acting regulatory elements were shown in Figure 4 and Table S4. There exist multiple phytohormone responsive elements including ABA response element (ABRE), auxin-responsive element (AuxRR, AuxRR-core, and TGA-element), ethylene-responsive element (ERE), MeJA-responsive element (CGTCA-motif), GA-responsive element (GARE-motif, P-box, and TATC-box), and salicylic acid-responsive element (TCA-element), suggesting that $M t C D P K s$ and $M t C R K s$ expression were regulated by different phytohormones. A variety of elements related to light-responsive elements were observed. The stress-responsive elements were found in the promoter of some MtCDPKs and MtCRKs, such as anaerobic induction element (ARE), dehydration-responsive element (DRE1 and DRE-core), drought-inducibility element (MBS), low-temperature-responsive element (LTR), defense and stress-responsive element (TC-rich repeats), stress-responsive element (STRE) and wound-responsive element (WRE3 and WUN-motif). Multiple growth and development elements were investigated, including endosperm-expression element (AACA-motif and GCN4-motif), meristem-expression element (CAT-box and CCGTCC-motif), circadian element, palisade mesophyll cells-expression element (HD-Zip 1), flavonoid biosynthetic genes regulation element (MBSI), zein metabolism regulation element (O2-site), and seedspecific regulation element (RY-element). Overall, two phytohormone responsive elements (ABRE and ERE) and two stress responsive elements (ARE and STRE) were detected in the promoter regions of most genes. But auxin-responsive elements, gibberellin-responsive elements, dehydration-responsive elements, and most of plant growth and development elements were found in the promoter regions of specific genes. The results indicated 
that $M t C D P K s$ and $M t C R K s$ are involved in plant growth and development as well as environmental stress responses.

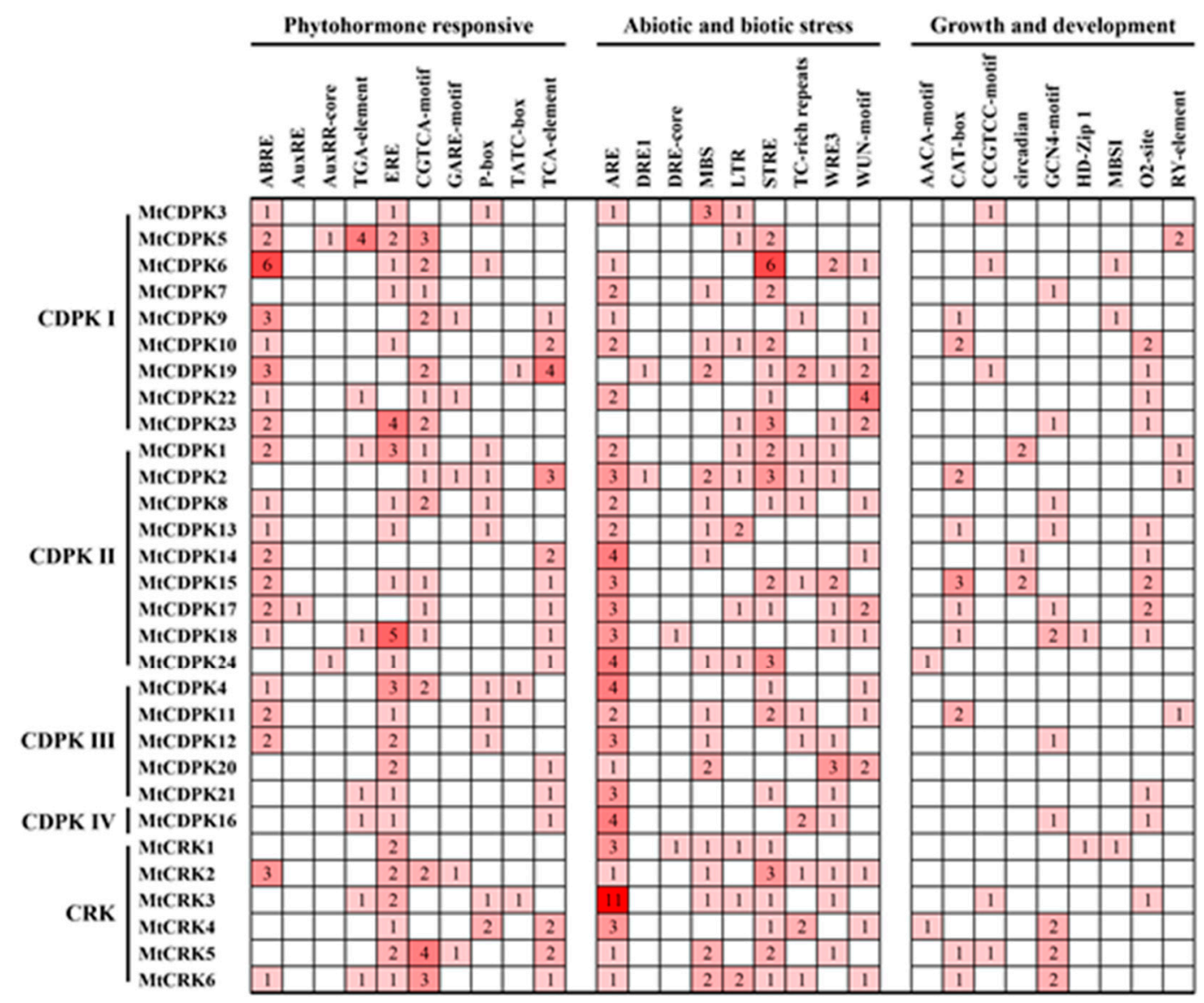

Figure 4. Cis-acting regulatory elements in the promoter region of $M t C D P K$ and $M t C R K$ genes. According to the function annotation, the elements were divided into the following three main categories: phytohormone responsive, abiotic and biotic stresses, and plant growth and development. The numbers and the depth of red represent the frequency of the elements that occur in the promoter region.

\subsection{Spatial Expression Profiles of MtCDPK and MtCRK Genes}

The spatial expression pattern of MtCDPK and MtCRK genes was analyzed based on microarray data from the Medicago truncatula Gene Expression Atlas (MtGEA, https: //mtgea.noble.org/v3/). MtCDPK7, 17, 22, and MtCRK3, 6 transcripts level was lower than other genes. $M t C D P K 8,16,18,19,22,23$, and MtCRK1 transcript major observed in roots. MtCDPK17 and MtCRK2 were preferentially expressed in flower, while MtCDPK14, $M t C D P K 20$, and MtCRK4 transcript were low in leaf. MtCRK5, MtCDPK9, and MtCDPK20 transcript were decreased during seed development, while MtCDPK4 and MtCDPK19 were increased (Figure 5, Table S5). The results suggested that MtCDPK and MtCRK genes might have diverse functions in different tissues. Unfortunately, no information on eight $M t C D P K$ genes $(M t C D P K 1,2,5,6,10,11,12$, and 13) was available from MtGEA. 


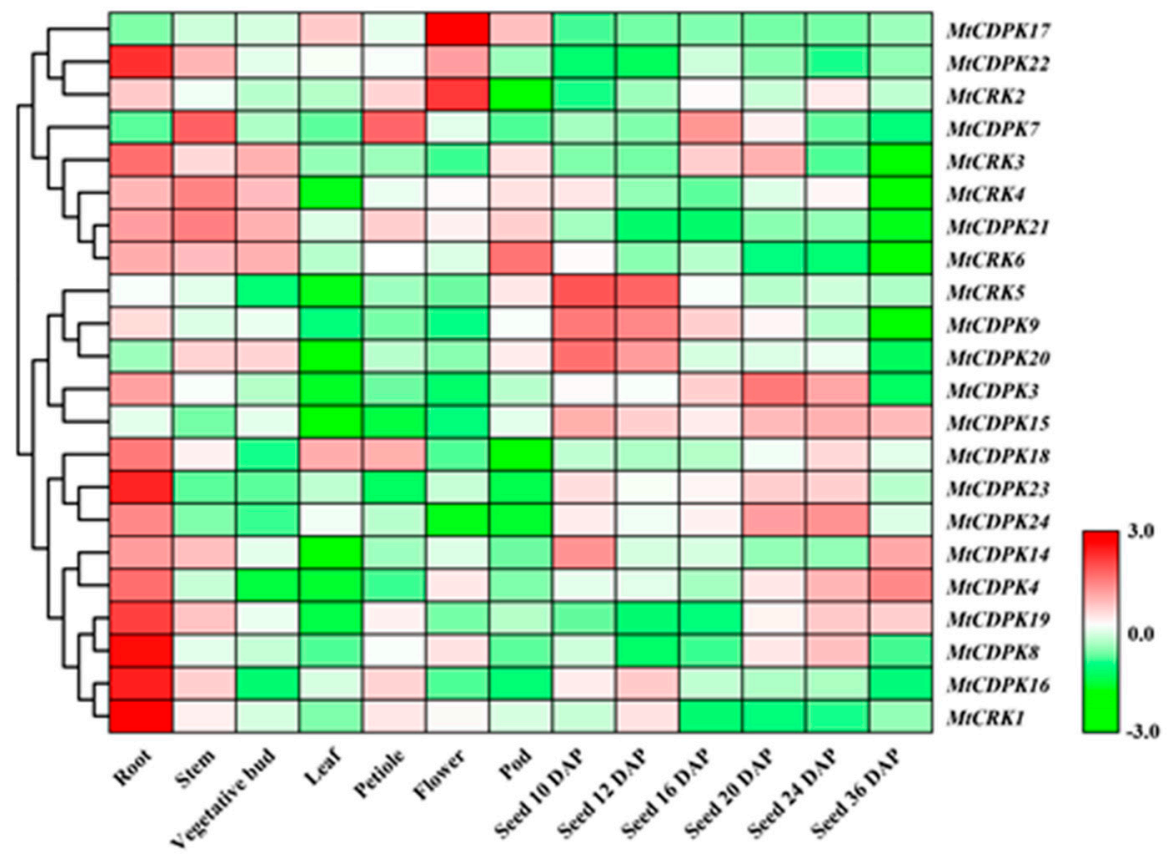

Figure 5. Expression patterns of $M t C D P K$ and $M t C R K$ genes in different developmental tissues. The microarray data were normalized based on the mean expression value of each gene in all organs analyzed. The heat map portrayed the relative expressions after $\log _{2}$ transformed. The corresponding group of each gene was shown on the left. DAP, days after pollination.

\subsection{Expression Patterns of MtCDPK and MtCRK Genes in Response to Abiotic and Biotic Stresses}

To analyze expression profiles of MtCDPKs and MtCRKs under abiotic stresses, available RNA-seq data were retrieved from NCBI (GEO database). Fragments per kilobase of exon per million fragments mapped (FPKM) values of MtCDPK1, 5, 6, 10, 11, and 13 were lower than 1 , which were considered to be barely expressed and not employed for analysis. $M t C D P K 4,8,15,16$, and 22 transcripts were quickly increased after $2 \mathrm{~h}$ of cold treatment. $M t C D P K 2$ transcript was increased continuously under drought stress, $M t C D P K 4,8,12$, $15,16,21$, and 22 transcripts were increased and peaked after $2 \mathrm{~h}$ of drought treatment, whereas MtCDPK22 transcript was decreased at $6 \mathrm{~h}$. In contrast, MtCDPK23 and MtCRK6 were downregulated after drought treatment. In response to salt treatment, $M t C D P K 2$, 4, 8, 12, and 16 transcripts were upregulated after salt stress, while $M t C R K 6, M t C D P K 7$, and MtCDPK17 transcripts were downregulated (Figure 6A and Table S6). The microarray data of treatment with yeast elicitor (YE) was used to analyze the responses of MtCDPKs and $M t C R K s$ to the pathogen. MtCDPK4, 8, 16, 18, 21, 22, and MtCRK1 were upregulated significantly at $2 \mathrm{~h}$ after treatment with yeast elicitor, whereas $M t C R K 4$ was downregulated (Figure $6 \mathrm{~B}$ and Table S7). The results indicated that MtCDPK and MtCRK genes showed diverse expression patterns under various stresses and may be involved in the regulation of abiotic and biotic stress responses. It is interesting that several MtCDPKs respond to multiple stresses. MtCDPK4, 8, and 16 were upregulated by cold, drought, salt, and pathogen, and MtCDPK12 were upregulated by cold, drought, and salt, while MtCDPK15 was upregulated by cold and drought. They are probably involved in plant adaptation to multiple stresses. 
A

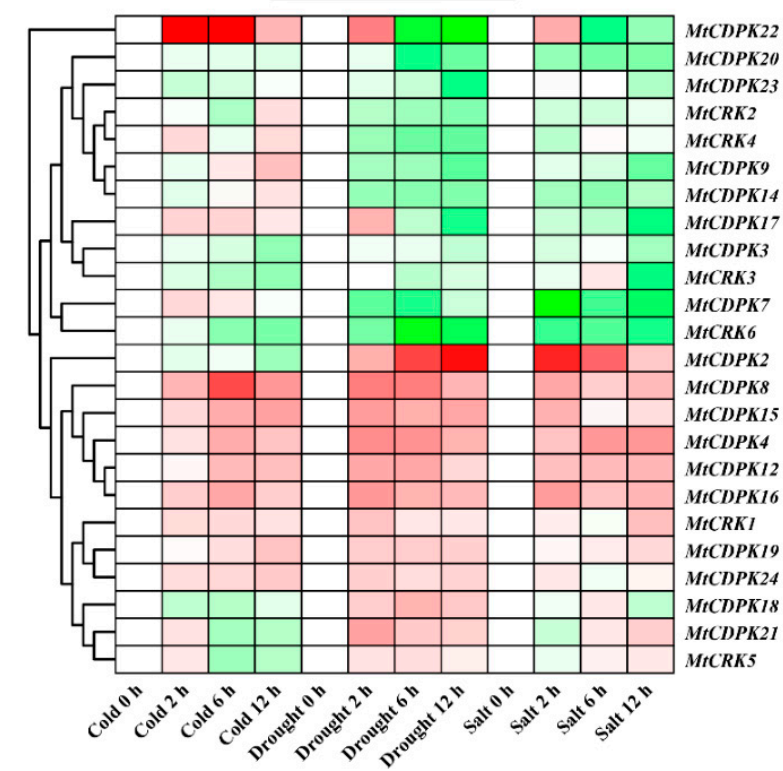

B
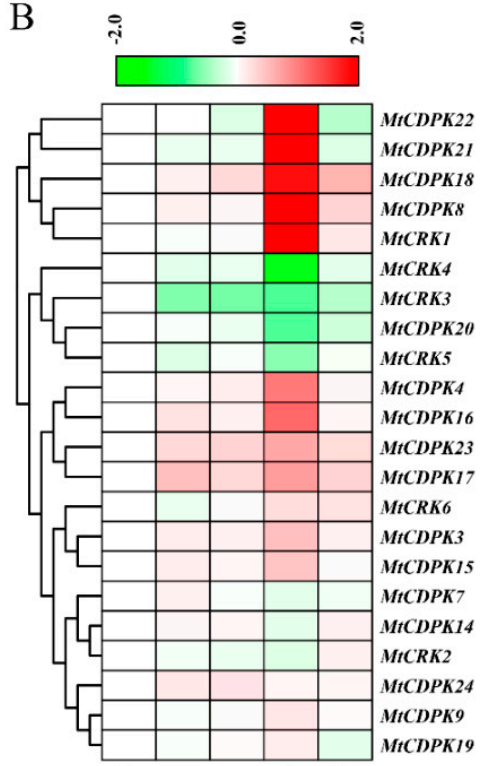

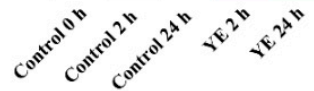

Figure 6. Expression patterns of $M t C D P K$ and $M t C R K$ genes under different abiotic treatments (A) and biotic treatment (B). The transcript levels after treatments were rescaled relative to that untreated time $($ at $0 \mathrm{~h})$ when calculating the relative expression levels. The heat map portrayed the relative expressions after $\log _{2}$ transformed. The corresponding group of each gene was shown on the left. YE, yeast elicitor.

\subsection{Subcellular Localization of Selected MtCDPKs and MtCRKs}

Subcellular localization of MtCDPK4, 7, 9, 14, 15, 16, 22, and MtCRK6 was analyzed to further explore the role of N-terminal acylation in protein localization. The selected MtCDPKs and MtCRKs covered all groups and types of modifications for $\mathrm{N}$-myristoylation and N-palmitoylation. The results showed that the fluorescence of MtCDPK4, 14, 16, 22, and MtCRK6 was co-localized with plasma membrane localization protein AtAKT1 after plasmolysis, indicating that they are localized on the plasma membrane. MtCDPK7, 9 , and 15, which lack one or both $\mathrm{N}$-acylation modification sites, were homogenously disseminated in cytosol and nucleus and highly overlapped with 35S::mCherry and as seen in the result of 35S::GFP signals (Figure 7).

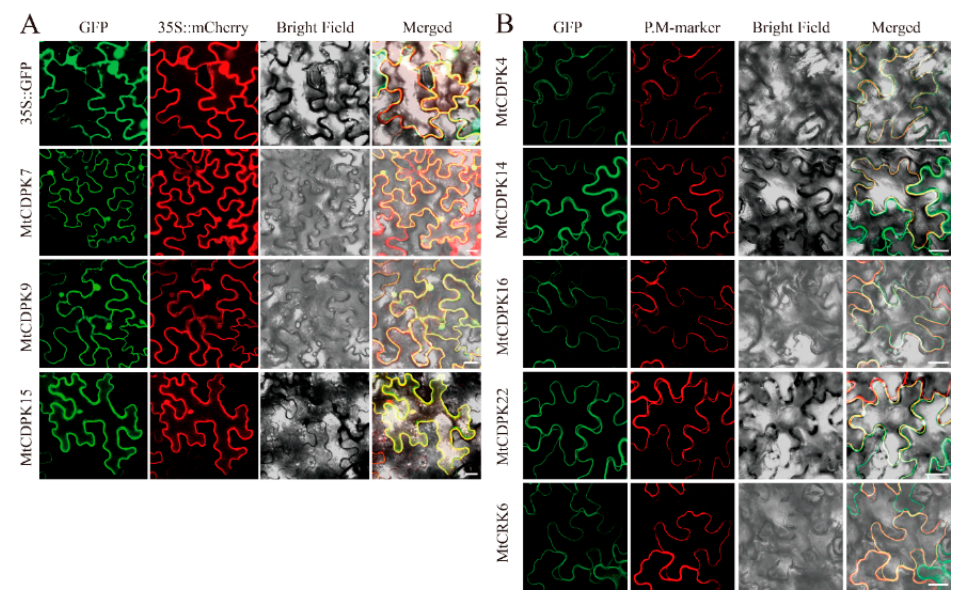

Figure 7. Subcellular localization of MtCDPKs- and MtCRKs-GFP fusion proteins in combination with 35S::mCherry (A) and PM-marker (B) by using the epidermal cells of N. benthamiana. The tobacco injected with P.M-marker was observed after plasmolysis. PM-marker: plasma membrane localization protein AtAKT1. Bars $=20 \mu \mathrm{m}$. 


\section{Discussion}

$C D P K$ and $C R K$ genes are present in photosynthetic organisms and play an important role in plant growth and development $[6,8]$. Comprehensive genome-wide identification of $C D P K$ and $C R K$ genes has been widely carried out in some plants, such as 34 CDPKs and eight CRKs in Arabidopsis [9], 31 CDPKs and five CRKs in rice [41], 29 CDPKs and six CRKs in tomato [34], 30 CDPKs and nine CRKs in poplar [42], and 49 CDPKs and 14 CRKs in Brassica rapa [43]. In the present study, six MtCRK genes were computationally identified, they and previously identified MtCDPKs were named as MtCDPK1 to MtCDPK24 and MtCRK1 to $M t C R K 6$ based on their chromosomal locations. Compared to previously identified 25 MtCDPKs, Doesn't Make Infections 3 (DMI3, Medtr8g043970) is a well-known protein kinase in Medicago truncatula, involving in nodule organogenesis [44]. It belongs to CCaMK, which binds not only calcium but also calmodulin, thus it was not included as CDPK in this study. MtCDPKs and MtCRKs are not distributed on every chromosome, which is consistent with that in poplar [42], soybean [45], and melon [46].

MtCDPKs and MtCRKs were divided into five groups (CDPK I to IV and CRK) based on the phylogenic tree among those in Arabidopsis, rice, and M. truncatula, which is consistent with that in other plant species [9,34,41-43]. The result indicates that CDPKs and CRKs are ubiquitous and conserved among plant species. MtCDPK and MtCRK members within the same group shared a similar exon-intron structure, intron phases, biochemical properties, and conserved motif compositions, indicating that they are closely evolutionary conservation. Compared to other groups, MtCRKs has a similar gene structure with the members in MtCDPK IV, and cluster with the MtCDPK IV group with 100\% bootstrap support. Furthermore, the theoretical pI of the members in the MtCRK and MtCDPK IV group tends to be moderately alkaline, while that of in other group shows slightly acidic. The above data are consistent with those in Arabidopsis, Brassica rapa, and watermelon, indicating that $C R K s$ may have evolved from MtCDPK IV $[9,43,47]$. The members in the same group shared highly similar gene structures and conserved motifs implied that they might have a similar function.

Gene duplication is a primary driving force for plant evolution and leads to the expansion of gene family. Gene duplication models include segmental/whole-genome duplication (WGD), tandem duplication, proximal duplication, transposed duplication, and dispersed duplication [48]. In our study, six pairs of segmental duplications were found in M. truncatula and 29 pairs of duplication events were found between M. truncatula and $A$. thaliana. Segmental duplication gene pairs were found in CDPK and CRK gene families in rice [41] and poplar [42]. Inter-genomic duplication events between Arabidopsis and other species have been reported. There are 22 collinear blocks of CDPK and CRK genes between melon and Arabidopsis [46]. The variation in the number of CDPK among species is associated with species-specific WGD events [6,8]. M. truncatula has experienced a high frequency of local genome rearrangement [49]. Our analysis indicated that segmental duplication plays a requisite role in MtCDPKs and MtCRKs expansion. Ka/Ks ratio was used to determine selection pressure on the duplicated gene pairs. The $\mathrm{Ka} / \mathrm{Ks}$ ratio of six paralogous genes was below 0.310. This is consistent with that in tomato [50] and Brassica rapa [43]. The result indicated that these pairs have been under strong purifying selection, which may cause limited functional divergence.

Multiple cis-acting elements responsible for phytohormones, stresses, growth and development were observed in the promoter regions of MtCDPKs and MtCRKs, indicating the potential role of $M t C D P K s$ and $M t C R K s$ in regulating multiple responses to phytohormones, environmental stresses, and development. The spatial expression of MtCDPKs and MtCRKs displays diversity, for instance, MtCDPK17 was exclusively expressed in flower, and its homologous genes AtCPK17 and AtCPK34 from Arabidopsis were reported to be involved in pollen tube growth [51]. CDPK and CRK family genes are involved in responding to various stresses, such as drought [22,23], salt [26], cold stress [27], and fungus and bacterial pathogens [31]. MtCDPK22 transcript is specifically and strongly expressed under cold stress, and its homologous gene OsCPK17 is involved in cold stress 
response [27]. MtCDPK8 was highly induced under cold treatment, while its paralogous gene $M t C D P K 18$ was downregulated expression. Transcripts of MtCDPK4, 8, 16, 18, 21, and 22 were responsive to yeast elicitor treatment. AtCPK28, orthologous to MtCDPK16, was verified to be a negative regulator of PAMP-triggered immunity (PTI) [52]. The results indicated that MtCDPKs and MtCRKs had functional diversity in M. truncatula. MtCDPK2, 18, 19, and CRK1, which contains dehydration-responsive elements (DRE1 or DRE-core), were upregulated under drought stress. In Arabidopsis, some AtCPKs are involved in regulating phytohormone and abiotic stresses signaling when specific cis-acting elements were detected in the promoter regions $[23,53,54]$. Therefore, similarities and differences analysis of family members based on the expression pattern and promoter can provide candidate genes for further functional analysis at least in part.

Myristoylation and palmitoylation are unique among lipid modifications [55]. They anchor proteins to membranes through mutual coordination and promote the proteins to exercise physiological processes [56-59]. An N-myristoylation site and a palmitoylation site are contained in most CDPKs and determine the subcellular distribution of CDPK $[58,59]$. MtCDPK4, 14, 16, 22, and MtCRK6 harbor both N-myristoylation site and palmitoylation site and were anchored on plasma membrane, while MtCDPK7, 9, and 15 contain no or only one N-acylation site and were distributed in cytosol and nucleus. The results indicated that the $\mathrm{N}$-terminal acylation sites play a key role in the subcellular localization of MtCDPKs and MtCRKs. The subcellular localization of AtCDPK6 and NtCPK5 are also affected by myristoylation/palmitoylation sites mutations [12,60]. Myristoylationregulated membrane association is loose, while palmitoylation confers stable membrane anchoring. Previous studies have shown that palmitoylation generally occurs at a Cys residue proximal to an $\mathrm{N}$-myristoylation site, indicating that palmitoylation-regulated membrane association might require the participation of N-myristoylation [61-63]. In addition, palmitoylation is reversible, which allows membrane-localized proteins to detach from the membrane and translocate to the cytosol or nucleus via thioesterase-mediated de$S$-palmitoylation [64,65]. Previous reports indicated that subcellular locations of AtCPK10, AtCPK30, and AtCPK32 were changed from plasma membrane to nucleus in response to nitrate [66]. Changes in subcellular localization provide the possibility for CDPKs and CRKs to perform different physiological functions. This study provides a foundation to further explore the functions of MtCDPKs and MtCRKs in M. truncatula.

\section{Materials and Methods}

\subsection{Identification of MtCRK Genes}

The sequences of $C R K$ genes were obtained from genome databases of Arabidopsis (TAIR, http://www.arabidopsis.org/), rice (TIGR, http:// rice.tigr.org), and Medicago truncatula (http:/ /www.medicagohapmap.org/) respectively. The amino acid sequences of CRKs of Arabidopsis and rice were used as reference sequences to search predicted homologs in Medicago truncatula using HMMER3.0 Software (http://hmmer.org/). The candidate $C R K$ genes were preliminarily identified by screen the gene using threshold of E-value (full sequence and best 1 domain) less than $1 \mathrm{E}-100$. The composition of identified candidate proteins was further verified in SMART databases (http://smart.embl-heidelberg.de/) [67] and NCBI-Conserved Domain database (CDD, https:/ / www.ncbi.nlm.nih.gov /Structure/ cdd/wrpsb.cgi), while the sequences with errors, shorter length ( $<100 \mathrm{aa})$, and containing incomplete Ser/Thr kinase domain were eliminated. The longest one was chosen for further analysis if a gene had alternative splice variants.

\subsection{Sequence Analysis of MtCDPKs and MtCRKs}

Molecular weight (MW), isoelectronic points (pI), and the grand average of hydropathy (GRAVY) of MtCDPKs and MtCRKs were predicted using The ExPASY PROTPARAM tool (http:/ / web.expasy.org/protparam/). The EF-hands motif was predicted using the ScanProsite tool (https:/ / prosite.expasy.org/prosite.html). The N-terminal myristoylation 
and palmitoylation sites were predicted using GPS-Lipid 1.0 program with default settings and high threshold [68].

\subsection{Multiple Sequence Alignments and Phylogenetic Analysis}

Multiple alignments of CDPK and CRK protein sequences from M. truncatula, Arabidopsis, and rice were performed using the MUSCLE program, which has a higher efficiency than CLUSTAL, with default parameters implemented in MEGA7.0 software (https://www.megasoftware.net/). The phylogenetic tree was constructed by using MEGA7.0 with the neighbor-joining method, and the 1000 bootstrap replicated by the Jones, Taylor, and Thornton amino acid substitution model (JTT model) and keeping the other parameters as a default to determine the reliability of the resulting tree [69].

\subsection{Gene Structure and Conserved Motifs Analysis}

The gene structure and conserved motifs were displayed using TBtools software [70]. The conserved motifs of each protein were analyzed using the MEME program (Version 5.1.1) (http:/ / meme-suite.org/tools/meme) [71]. The maximum motif number was set as 20 , and the other parameters as default.

\subsection{Chromosomal Location and Synteny Correlation Analysis}

For analysis of chromosomal locations of $M t C D P K$ and $M t C R K$ genes, the Circos diagram was illustrated by annotating genes on their specific chromosomal position in the genome annotation using TBtools software. The syntenic gene relationships between the homologs of $A$. thaliana and $M$. truncatula were verified and visualized using the Circos tool implemented in TBtools software.

\subsection{Calculation of Ka/Ks Ratios of Paralogous Gene Pairs of MtCDPKs and MtCRKs}

The nonsynonymous $(K a)$ and synonymous $(K s)$ substitution rates of paralogous gene pairs of MtCDPKs and MtCRKs were calculated based on the standard genetic codon table using the Nei-Gojobori method (Jukes-Cantor model) in MEGA 7.0 [69].

\subsection{Analysis of Cis-Acting Regulatory Elements in Promoter Regions}

A $2.0 \mathrm{~kb}$ of promoter sequence upstream from the transcription start site in each $M t C D P K$ and MtCRK was extracted from the $M$. truncatula genome database and analyzed using PlantCARE online software (http:/ / bioinformatics.psb.ugent.be/webtools / plantcare $/ \mathrm{html} /$ ) to predict the putative cis-acting regulatory elements [72].

\subsection{Analysis of Expression Profiles of MtCDPKs and MtCRKs}

Microarray data on the expression profile of MtCDPKs and MtCRKs in roots, stem, vegetative bud, leaf, petiole, flower, pods, and seeds and responses to pathogen were extracted from the MtGEA (https:/ / mtgea.noble.org/v3/) [73]. The probe with the maximum value was selected for the subsequent analysis when a gene corresponds to multiple probes. The microarray data were normalized based on the mean expression value of each gene in all organs analyzed, while the normalized data were used to generate the heatmap using the TBtools software. The expression pattern of MtCDPKs and MtCRKs in response to cold, drought, and salt stresses was from NCBI GEO with the dataset accession of GSE136739 [74]. FPKM was used for representing the expression abundance of each $M t C D P K$ and $M t C R K$ gene. The relative transcript level after treatments was calculated compared with the control before treatment $(0 \mathrm{~h})$. The clustered heatmap was portrayed based on the relative expression using the TBtools software.

\subsection{Analysis of Subcellular Localization}

The coding sequence without the terminal codon of selected MtCDPKs and MtCRKs was amplified using specific primer pairs and inserted into the expression vector pCAMBIA1305-GFP driven by CaMV 35S promoter utilizing homologous recombination (Table S8). 
Agrobacterium tumefaciens EHA105 harboring the constructed vectors or empty vector in combination with 35S::mCherry vector or 35S::AtAKT1-mCherry vector were used to cotransform the abaxial surfaces of leaves of 4-week-old $N$. benthamiana. Then the tobaccos were grown under normal condition. Before the observation, the tobacco injected with P.M-marker was immersed in $0.3 \mathrm{~g} / \mathrm{mL}$ sucrose solution for plasmolysis. Fluorescence was observed using confocal laser scanning microscopy (Zeiss LSM800, Germany) at $72 \mathrm{~h}$ after transformation.

Supplementary Materials: The following are available online at https:/ / www.mdpi.com/1422-006 7/22/3/1044/s1.

Author Contributions: Z.G. and P.Z. designed the research and wrote the article. P.Z. and Y.L. collected data and performed most of the data analysis. W.K. participated in the revision of the manuscript. J.J. and T.C. performed the experiments. All authors have read and agreed to the published version of the manuscript.

Funding: This work was supported by the National Natural Science Foundation of China (Grant number: 32030074).

Institutional Review Board Statement: Not applicable.

Informed Consent Statement: Not applicable.

Data Availability Statement: The data that support the findings of this study are available from the corresponding author upon reasonable request.

Conflicts of Interest: The authors declare no conflict of interest.

\section{References}

1. Trewavas, A.J.; Malho, R. Ca ${ }^{2+}$ signalling in plant cells: The big network! Curr. Opin. Plant Biol. 1998, 1, 428-433. [CrossRef]

2. Dodd, A.N.; Kudla, J.; Sanders, D. The language of calcium signaling. Annu. Rev. Plant Biol. 2010, 61, 593-620. [CrossRef] [PubMed]

3. Marcec, M.J.; Gilroy, S.; Poovaiah, B.W.; Tanaka, K. Mutual interplay of $\mathrm{Ca}(2+)$ and ROS signaling in plant immune response. Plant Sci. 2019, 283, 343-354. [CrossRef]

4. Tian, W.; Wang, C.; Gao, Q.; Li, L.; Luan, S. Calcium spikes, waves and oscillations in plant development and biotic interactions. Nat. Plants 2020, 6, 750-759. [CrossRef]

5. Batistic, O.; Kudla, J. Analysis of calcium signaling pathways in plants. Biochim. Biophys. Acta 2012, 1820, 1283-1293. [CrossRef]

6. Schulz, P.; Herde, M.; Romeis, T. Calcium-dependent protein kinases: Hubs in plant stress signaling and development. Plant Physiol. 2013, 163, 523-530. [CrossRef]

7. Harper, J.F.; Breton, G.; Harmon, A. Decoding Ca ${ }^{2+}$ signals through plant protein kinases. Annu. Rev. Plant Biol. 2004, 55, 263-288. [CrossRef]

8. Valmonte, G.R.; Arthur, K.; Higgins, C.M.; MacDiarmid, R.M. Calcium-dependent protein kinases in plants: Evolution, expression and function. Plant Cell Physiol. 2014, 55, 551-569. [CrossRef]

9. Hrabak, E.M.; Chan, C.W.; Gribskov, M.; Harper, J.F.; Choi, J.H.; Halford, N.; Kudla, J.; Luan, S.; Nimmo, H.G.; Sussman, M.R.; et al. The Arabidopsis CDPK-SnRK superfamily of protein kinases. Plant Physiol. 2003, 132, 666-680. [CrossRef] [PubMed]

10. Harmon, A.C.; Gribskov, M.; Gubrium, E.; Harper, J.F. The CDPK superfamily of protein kinases. New Phytol. 2001, 151, 175-183. [CrossRef]

11. Resh, M.D. Trafficking and signaling by fatty-acylated and prenylated proteins. Nat. Chem. Biol. 2006, 2, 584-590. [CrossRef] [PubMed]

12. Saito, S.; Hamamoto, S.; Moriya, K.; Matsuura, A.; Sato, Y.; Muto, J.; Noguchi, H.; Yamauchi, S.; Tozawa, Y.; Ueda, M.; et al. $\mathrm{N}$-myristoylation and S-acylation are common modifications of $\mathrm{Ca}^{2+}$-regulated Arabidopsis kinases and are required for activation of the SLAC1 anion channel. New Phytol. 2018, 218, 1504-1521. [CrossRef] [PubMed]

13. Zhao, L.N.; Shen, L.K.; Zhang, W.Z.; Zhang, W.; Wang, Y.; Wu, W.H. Ca ${ }^{2+}$-dependent protein kinase11 and 24 modulate the activity of the inward rectifying $\mathrm{K}^{+}$channels in Arabidopsis pollen tubes. Plant Cell 2013, 25, 649-661. [CrossRef] [PubMed]

14. Wu, Y.; Zhao, S.; Tian, H.; He, Y.; Xiong, W.; Guo, L.; Wu, Y. CPK3-phosphorylated RhoGDI1 is essential in the development of Arabidopsis seedlings and leaf epidermal cells. J. Exp. Bot. 2013, 64, 3327-3338. [CrossRef]

15. Matschi, S.; Werner, S.; Schulze, W.X.; Legen, J.; Hilger, H.H.; Romeis, T. Function of calcium-dependent protein kinase CPK28 of Arabidopsis thaliana in plant stem elongation and vascular development. Plant J. 2013, 73, 883-896. [CrossRef]

16. Vijayakumar, P.; Datta, S.; Dolan, L. ROOT HAIR DEFECTIVE SIX-LIKE4 (RSL4) promotes root hair elongation by transcriptionally regulating the expression of genes required for cell growth. New Phytol. 2016, 212, 944-953. [CrossRef] 
17. Rigo, G.; Ayaydin, F.; Tietz, O.; Zsigmond, L.; Kovacs, H.; Pay, A.; Salchert, K.; Darula, Z.; Medzihradszky, K.F.; Szabados, L.; et al. Inactivation of plasma membrane-localized CDPK-RELATED KINASE5 decelerates PIN2 exocytosis and root gravitropic response in Arabidopsis. Plant Cell 2013, 25, 1592-1608. [CrossRef]

18. Baba, A.I.; Rigo, G.; Ayaydin, F.; Rehman, A.U.; Andrasi, N.; Zsigmond, L.; Valkai, I.; Urbancsok, J.; Vass, I.; Pasternak, T.; et al. Functional analysis of the Arabidopsis thaliana CDPK-related kinase family: AtCRK1 regulates responses to continuous light. Int. J. Mol. Sci. 2018, 19, 1282. [CrossRef]

19. Kawamoto, N.; Endo, M.; Araki, T. Expression of a kinase-dead form of CPK33 involved in florigen complex formation causes delayed flowering. Plant Signal Behav. 2015, 10, e1086856. [CrossRef]

20. Morello, L.; Frattini, M.; Giani, S.; Christou, P.; Breviario, D. Overexpression of the calcium-dependent protein kinase OsCDPK2 in transgenic rice is repressed by light in leaves and disrupts seed development. Transgenic Res. 2000, 9, 453-462. [CrossRef]

21. Durian, G.; Sedaghatmehr, M.; Matallana-Ramirez, L.P.; Schilling, S.M.; Schaepe, S.; Guerra, T.; Herde, M.; Witte, C.P.; MuellerRoeber, B.; Schulze, W.X.; et al. Calcium-dependent protein kinase CPK1 controls cell death by in vivo phosphorylation of senescence master regulator ORE1. Plant Cell 2020, 32, 1610-1625. [CrossRef] [PubMed]

22. Edel, K.H.; Kudla, J. Integration of calcium and ABA signaling. Curr. Opin. Plant Biol. 2016, 33, 83-91. [CrossRef] [PubMed]

23. Zhang, H.F.; Liu, D.Y.; Yang, B.; Liu, W.Z.; Mu, B.B.; Song, H.X.; Chen, B.Y.; Li, Y.; Ren, D.T.; Deng, H.Q.; et al. Arabidopsis CPK6 positively regulates ABA signaling and drought tolerance through phosphorylating ABA-responsive element-binding factors. $J$. Exp. Bot. 2020, 71, 188-203. [CrossRef] [PubMed]

24. Zou, J.J.; Li, X.D.; Ratnasekera, D.; Wang, C.; Liu, W.X.; Song, L.F.; Zhang, W.Z.; Wu, W.H. Arabidopsis CALCIUM-DEPENDENT PROTEIN KINASE8 and CATALASE3 function in abscisic acid-mediated Signaling and $\mathrm{H}_{2} \mathrm{O}_{2}$ Homeostasis in Stomatal Guard Cells under Drought Stress. Plant Cell 2015, 27, 1445-1460. [CrossRef] [PubMed]

25. Asano, T.; Hayashi, N.; Kobayashi, M.; Aoki, N.; Miyao, A.; Mitsuhara, I.; Ichikawa, H.; Komatsu, S.; Hirochika, H.; Kikuchi, S.; et al. A rice calcium-dependent protein kinase OsCPK12 oppositely modulates salt-stress tolerance and blast disease resistance. Plant J. 2012, 69, 26-36. [CrossRef]

26. Latz, A.; Mehlmer, N.; Zapf, S.; Mueller, T.D.; Wurzinger, B.; Pfister, B.; Csaszar, E.; Hedrich, R.; Teige, M.; Becker, D. Salt stress triggers phosphorylation of the Arabidopsis vacuolar $\mathrm{K}^{+}$channel TPK1 by calcium-dependent protein kinases (CDPKs). Mol. Plant 2013, 6, 1274-1289. [CrossRef]

27. Almadanim, M.C.; Alexandre, B.M.; Rosa, M.T.G.; Sapeta, H.; Leitao, A.E.; Ramalho, J.C.; Lam, T.T.; Negrao, S.; Abreu, I.A.; Oliveira, M.M. Rice calcium-dependent protein kinase OsCPK17 targets plasma membrane intrinsic protein and sucrosephosphate synthase and is required for a proper cold stress response. Plant Cell Environ. 2017, 40, 1197-1213. [CrossRef]

28. Wang, S.; Tao, Y.; Zhou, Y.L.; Niu, J.; Shu, Y.J.; Yu, X.W.; Liu, S.S.; Chen, M.; Gu, W.H.; Ma, H. Translationally controlled tumor protein GmTCTP interacts with GmCDPKSK5 in response to high temperature and humidity stress during soybean seed development. Plant Growth Regul. 2017, 82, 187-200. [CrossRef]

29. Tao, X.; Lu, Y. Loss of AtCRK1 gene function in Arabidopsis thaliana decreases tolerance to salt. J. Plant Biol. 2013, 56, 306-314. [CrossRef]

30. Liu, H.T.; Gao, F.; Li, G.L.; Han, J.L.; Liu, D.L.; Sun, D.Y.; Zhou, R.G. The calmodulin-binding protein kinase 3 is part of heat-shock signal transduction in Arabidopsis thaliana. Plant J. 2008, 55, 760-773. [CrossRef]

31. Coca, M.; Segundo, B. AtCPK1 calcium-dependent protein kinase mediates pathogen resistance in Arabidopsis. Plant J. 2010, 63, 526-540. [CrossRef] [PubMed]

32. Gravino, M.; Savatin, D.V.; Macone, A.; De Lorenzo, G. Ethylene production in Botrytis cinerea- and oligogalacturonide-induced immunity requires calcium-dependent protein kinases. Plant J. 2015, 84, 1073-1086. [CrossRef] [PubMed]

33. Dubiella, U.; Seybold, H.; Durian, G.; Komander, E.; Lassig, R.; Witte, C.P.; Schulze, W.X.; Romeis, T. Calcium-dependent protein kinase/NADPH oxidase activation circuit is required for rapid defense signal propagation. Proc. Natl. Acad. Sci. USA 2013, 110, 8744-8749. [CrossRef] [PubMed]

34. Wang, J.P.; Xu, Y.P.; Munyampundu, J.P.; Liu, T.Y.; Cai, X.Z. Calcium-dependent protein kinase (CDPK) and CDPK-related kinase (CRK) gene families in tomato: Genome-wide identification and functional analyses in disease resistance. Mol. Genet Genomics 2016, 291, 661-676. [CrossRef]

35. Ivashuta, S.; Liu, J.; Liu, J.; Lohar, D.P.; Haridas, S.; Bucciarelli, B.; VandenBosch, K.A.; Vance, C.P.; Harrison, M.J.; Gantt, J.S. RNA interference identifies a calcium-dependent protein kinase involved in Medicago truncatula root development. Plant Cell 2005, 17, 2911-2921. [CrossRef]

36. Gargantini, P.R.; Gonzalez-Rizzo, S.; Chinchilla, D.; Raices, M.; Giammaria, V.; Ulloa, R.M.; Frugier, F.; Crespi, M.D. A CDPK isoform participates in the regulation of nodule number in Medicago truncatula. Plant J. 2006, 48, 843-856. [CrossRef]

37. Yu, H.; Xiao, A.; Dong, R.; Fan, Y.; Zhang, X.; Liu, C.; Wang, C.; Zhu, H.; Duanmu, D.; Cao, Y.; et al. Suppression of innate immunity mediated by the CDPK-Rboh complex is required for rhizobial colonization in Medicago truncatula nodules. New Phytol. 2018, 220, 425-434. [CrossRef]

38. Delormel, T.Y.; Boudsocq, M. Properties and functions of calcium-dependent protein kinases and their relatives in Arabidopsis thaliana. New Phytol. 2019, 224, 585-604. [CrossRef]

39. Vighi, I.L.; Crizel, R.L.; Perin, E.C.; Rombaldi, C.V.; Galli, V. Crosstalk During Fruit Ripening and Stress Response Among Abscisic Acid, Calcium-Dependent Protein Kinase and Phenylpropanoid. Crit. Rev. Plant Sci. 2019, 38, 99-116. [CrossRef] 
40. Gong, J.; Zhang, Y.; Li, F.; He, X.; Zhang, X.; Yi, Y. Bioinformation anlysis of Calcium-dependent protein kinase family of Medicago truncatula. Mol. Plant Breed. 2018, 9, 26-35.

41. Asano, T.; Tanaka, N.; Yang, G.; Hayashi, N.; Komatsu, S. Genome-wide identification of the rice calcium-dependent protein kinase and its closely related kinase gene families: Comprehensive analysis of the CDPKs gene family in rice. Plant Cell Physiol. 2005, 46, 356-366. [CrossRef]

42. Zuo, R.; Hu, R.; Chai, G.; Xu, M.; Qi, G.; Kong, Y.; Zhou, G. Genome-wide identification, classification, and expression analysis of CDPK and its closely related gene families in poplar (Populus trichocarpa). Mol. Biol. Rep. 2013, 40, 2645-2662. [CrossRef]

43. Wu, P.; Wang, W.; Duan, W.; Li, Y.; Hou, X. Comprehensive analysis of the CDPK-SnRK superfamily genes in Chinese cabbage and its evolutionary implications in plants. Front. Plant Sci. 2017, 8, 162. [CrossRef] [PubMed]

44. Rival, P.; de Billy, F.; Bono, J.J.; Gough, C.; Rosenberg, C.; Bensmihen, S. Epidermal and cortical roles of NFP and DMI3 in coordinating early steps of nodulation in Medicago truncatula. Development 2012, 139, 3383-3391. [CrossRef] [PubMed]

45. Liu, H.; Che, Z.; Zeng, X.; Zhou, X.; Sitoe, H.M.; Wang, H.; Yu, D. Genome-wide analysis of calcium-dependent protein kinases and their expression patterns in response to herbivore and wounding stresses in soybean. Funct. Integr. Genomics 2016, 16, 481-493. [CrossRef] [PubMed]

46. Zhang, H.F.; Wei, C.H.; Yang, X.Z.; Chen, H.J.; Yang, Y.C.; Mo, Y.L.; Li, H.; Zhang, Y.; Ma, J.X.; Yang, J.Q.; et al. Genome-wide identification and expression analysis of calcium-dependent protein kinase and its related kinase gene families in melon (Cucumis melo L.). PLoS ONE 2017, 12, e0176352. [CrossRef] [PubMed]

47. Wei, C.; Zhang, R.; Yang, X.; Zhu, C.; Li, H.; Zhang, Y.; Ma, J.; Yang, J.; Zhang, X. Comparative analysis of calcium-dependent protein kinase in Cucurbitaceae and expression studies in watermelon. Int. J. Mol. Sci. 2019, 20, 2527. [CrossRef] [PubMed]

48. Paterson, A.H.; Freeling, M.; Tang, H.; Wang, X. Insights from the comparison of plant genome sequences. Annu. Rev. Plant Biol. 2010, 61, 349-372. [CrossRef]

49. Young, N.D.; Debelle, F.; Oldroyd, G.E.D.; Geurts, R.; Cannon, S.B.; Udvardi, M.K.; Benedito, V.A.; Mayer, K.F.X.; Gouzy, J.; Schoof, H.; et al. The Medicago genome provides insight into the evolution of rhizobial symbioses. Nature 2011, 480, 520-524. [CrossRef]

50. Hu, Z.; Lv, X.; Xia, X.; Zhou, J.; Shi, K.; Yu, J.; Zhou, Y. Genome-wide identification and expression analysis of calcium-dependent protein kinase in tomato. Front. Plant Sci. 2016, 7, 469. [CrossRef]

51. Myers, C.; Romanowsky, S.M.; Barron, Y.D.; Garg, S.; Azuse, C.L.; Curran, A.; Davis, R.M.; Hatton, J.; Harmon, A.C.; Harper, J.F. Calcium-dependent protein kinases regulate polarized tip growth in pollen tubes. Plant J. 2009, 59, 528-539. [CrossRef] [PubMed]

52. Monaghan, J.; Matschi, S.; Shorinola, O.; Rovenich, H.; Matei, A.; Segonzac, C.; Malinovsky, F.G.; Rathjen, J.P.; MacLean, D.; Romeis, T.; et al. The calcium-dependent protein kinase CPK28 buffers plant immunity and regulates BIK1 turnover. Cell Host Microbe 2014, 16, 605-615. [CrossRef] [PubMed]

53. Li, C.L.; Wang, M.; Wu, X.M.; Chen, D.H.; Lv, H.J.; Shen, J.L.; Qiao, Z.; Zhang, W. THI1, a thiamine thiazole synthase, interacts with $\mathrm{Ca}^{2+}$-dependent protein kinase CPK33 and modulates the S-Type anion channels and stomatal closure in Arabidopsis. Plant Physiol. 2016, 170, 1090-1104. [CrossRef]

54. Huang, K.; Peng, L.; Liu, Y.; Yao, R.; Liu, Z.; Li, X.; Yang, Y.; Wang, J. Arabidopsis calcium-dependent protein kinase AtCPK1 plays a positive role in salt/drought-stress response. Biochem. Biophys. Res. Commun. 2018, 498, 92-98. [CrossRef]

55. Hemsley, P.A. The importance of lipid modified proteins in plants. New Phytol. 2015, 205, 476-489. [CrossRef] [PubMed]

56. Liu, J.; Zhong, S.; Guo, X.; Hao, L.; Wei, X.; Huang, Q.; Hou, Y.; Shi, J.; Wang, C.; Gu, H.; et al. Membrane-bound RLCKs LIP1 and LIP2 are essential male factors controlling male-female attraction in Arabidopsis. Curr. Biol. 2013, 23, 993-998. [CrossRef] [PubMed]

57. Hurst, C.H.; Hemsley, P.A. Current perspective on protein S-acylation in plants: More than just a fatty anchor? J. Exp. Bot. 2015, 66, 1599-1606. [CrossRef]

58. Simeunovic, A.; Mair, A.; Wurzinger, B.; Teige, M. Know where your clients are: Subcellular localization and targets of calciumdependent protein kinases. J. Exp. Bot. 2016, 67, 3855-3872. [CrossRef]

59. Zheng, L.; Liu, P.; Liu, Q.; Wang, T.; Dong, J. Dynamic protein s-acylation in plants. Int. J. Mol. Sci. 2019, 20, 560. [CrossRef]

60. Wang, Y.; Zhang, M.; Ke, K.; Lu, Y.T. Cellular localization and biochemical characterization of a novel calcium-dependent protein kinase from tobacco. Cell Res. 2005, 15, 604-612. [CrossRef]

61. Galbiati, F.; Guzzi, F.; Magee, A.I.; Milligan, G.; Parenti, M. N-terminal fatty acylation of the alpha-subunit of the G-protein G(I)1-only the myristoylated protein is a substrate for palmitoylation. Biochem. J. 1994, 303, 697-700. [CrossRef] [PubMed]

62. Resh, M.D. Fatty acylation of proteins: New insights into membrane targeting of myristoylated and palmitoylated proteins. BBA-Mol. Cell Res. 1999, 1451, 1-16. [CrossRef]

63. Hemsley, P.A.; Weimar, T.; Lilley, K.S.; Dupree, P.; Grierson, C.S. A proteomic approach identifies many novel palmitoylated proteins in Arabidopsis. New Phytol. 2013, 197, 805-814. [CrossRef] [PubMed]

64. Aicart-Ramos, C.; Valero, R.A.; Rodriguez-Crespo, I. Protein palmitoylation and subcellular trafficking. Biochim. Biophys. Acta 2011, 1808, 2981-2994. [CrossRef]

65. Duan, M.; Zhang, R.X.; Zhu, F.G.; Zhang, Z.Q.; Gou, L.M.; Wen, J.Q.; Dong, J.L.; Wang, T. A lipid-anchored NAC transcription factor is translocated into the nucleus and activates glyoxalase I expression during drought stress. Plant Cell 2017, 29, 1748-1772. [CrossRef] 
66. Liu, K.H.; Niu, Y.; Konishi, M.; Wu, Y.; Du, H.; Sun Chung, H.; Li, L.; Boudsocq, M.; McCormack, M.; Maekawa, S.; et al. Discovery of nitrate-CPK-NLP signalling in central nutrient-growth networks. Nature 2017, 545, 311-316. [CrossRef]

67. Letunic, I.; Khedkar, S.; Bork, P. SMART: Recent updates, new developments and status in 2020. Nucleic Acids Res. 2020, 49, D458-D460. [CrossRef]

68. Xie, Y.; Zheng, Y.; Li, H.; Luo, X.; He, Z.; Cao, S.; Shi, Y.; Zhao, Q.; Xue, Y.; Zuo, Z.; et al. GPS-Lipid: A robust tool for the prediction of multiple lipid modification sites. Sci. Rep. 2016, 6, 28249. [CrossRef]

69. Kumar, S.; Stecher, G.; Tamura, K. MEGA7: Molecular Evolutionary Genetics Analysis Version 7.0 for Bigger Datasets. Mol. Biol. Evol. 2016, 33, 1870-1874. [CrossRef]

70. Chen, C.J.; Chen, H.; Zhang, Y.; Thomas, H.R.; Frank, M.H.; He, Y.H.; Xia, R. TBtools: An integrative toolkit developed for interactive analyses of big biological data. Mol. Plant 2020, 13, 1194-1202. [CrossRef]

71. Bailey, T.L.; Boden, M.; Buske, F.A.; Frith, M.; Grant, C.E.; Clementi, L.; Ren, J.; Li, W.W.; Noble, W.S. MEME SUITE: Tools for motif discovery and searching. Nucleic Acids Res. 2009, 37, W202-W208. [CrossRef] [PubMed]

72. Lescot, M.; Dehais, P.; Thijs, G.; Marchal, K.; Moreau, Y.; Van de Peer, Y.; Rouze, P.; Rombauts, S. PlantCARE, a database of plant cis-acting regulatory elements and a portal to tools for in silico analysis of promoter sequences. Nucleic Acids Res. 2002, 30, 325-327. [CrossRef] [PubMed]

73. Benedito, V.A.; Torres-Jerez, I.; Murray, J.D.; Andriankaja, A.; Allen, S.; Kakar, K.; Wandrey, M.; Verdier, J.; Zuber, H.; Ott, T.; et al. A gene expression atlas of the model legume Medicago truncatula. Plant J. 2008, 55, 504-513. [CrossRef] [PubMed]

74. Song, J.; Mo, X.; Yang, H.; Yue, L.; Song, J.; Mo, B. The U-box family genes in Medicago truncatula: Key elements in response to salt, cold, and drought stresses. PLoS ONE 2017, 12, e0182402. [CrossRef] [PubMed] 